\section{Diffraction of Electrons in Mercury Vapour}

Two years ago, while investigating the angular scattering of electrons in mercury vapour, $I$ found well-marked diffraction effects. ${ }^{1}$ In that investigation, results were obtained over an angular range of $18^{\circ}$. $126^{\circ}$, and for velocities of the primary electron beam between 8 volts and 800 volts. It was later announced that the work was being extended to larger angles and to other vapours. ${ }^{2}$ The apparatus has now been modified to enable results to be obtained for angles up to $175^{\circ}$.

In Fig. 1 some typical results for mercury vapour are shown. An interesting feature of the new results

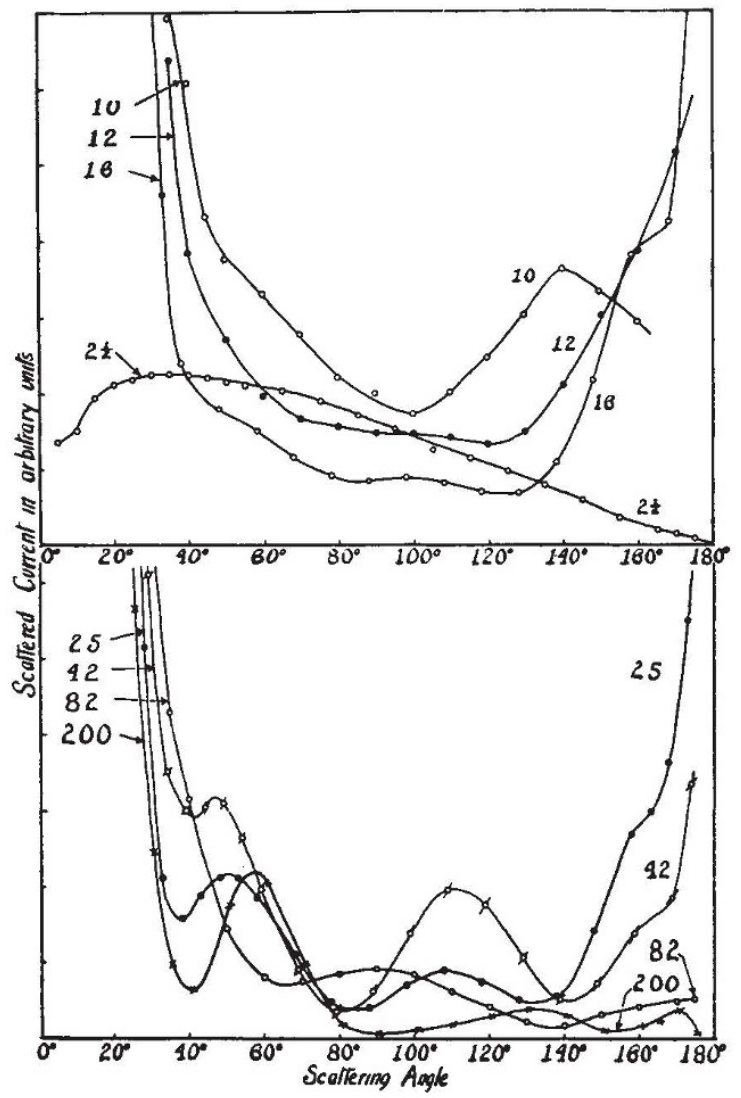

Fir. 1.

is the strong backward scattering of electrons having energies between about 50 volts and 10 volts. This feature has also been found to occur in the rare gases by Ramsauer and Kollath, ${ }^{3}$ and in argon by Hughes and McMillen.4

In addition to the results given in Fig. 1, curves have been obtained for a number of intermediate voltages. As these curves merely show transition stages between the curves reproduced here, they have been omitted in this preliminary report. A full account of this work will be published shortly, and in the meantime other vapours will be investigated.

\section{F. L. Arnot.}

University of St. Andrews, Aug. 12.

1 F. L. Arnot, Proc. Roy. Soc., A, 130, 655; 1931.

F. L. Arnot, Proc. Roy. Soc., A, 133, 615; 1931 .

- Ramsauer and Kollath, Ann. d. Phys., 12, 837; 1932.

- Hughes and McMillen, Phys. Rev., 39, 585; 1932.

No. 3281, VoL. 130]

\section{Sir Richard Threlfall and the Automatic Microtome}

The appreciative notices of Sir Richard Threlfall which have appeared in NATURE have made no reference to what was probably his first notable invention;- -and one that revolutionised an essential method of biological research. As a contemporary of his at Cambridge, among the first who had the opportunity of profiting by his results, I may per. haps be permitted to emphasise its importance. It had been realised for some time that the structure of an animal could be studied with great advantage with the aid of a complete series of sections arranged in order on microscopical slides. Until 1883 no satis factory method was known of preparing and mounting such a series. Each section had to be separately placed on the slide, where the material in which it had been embedded was dissolved. Parts of the section which were not connected with others floated away and were lost; and the sections already in place were disarranged, involving the necessity of readjusting many of them before the next section could be added. The work involved was extremely laborious, as I can state from personal experience, and the final result left much to be desired. These were, however, the methods with the aid of which F. M. Balfour established his reputation as an embryologist.

The credit of initiating a more satisfactory process is due to W. H. Caldwell, who ascertained that a section of an object embedded in a block of solid paraffin cut so that two of its edges were parallel to one another and to the edge of the knife to be used could be made to remain united on the razor. An important detail in this method was that the block of hard paraffin used for embedding was dipped, before cutting, in a paraffin of lower melting point, which served as the cement uniting consecutive sections. In 1882, Caldwell consulted Threlfall, then an undergraduate at his own College (Caius), leaving it to him to devise a machine which would produce the desired result. This object was duly accomplished; and the microtome, constructed in Prof. Stuart's workshop at Cambridge at Threlfall's expense, was completed in 1883 and proved an unqualified success. Its history has fortunately been recorded in a very recent paper by Threlfall (Biological Reviews, Cambridge, vol. 5 , p. 357 ; 1930), who stated that the only biological work he ever did at Cambridge was the preparation, with his microtome, of a complete series of sections of Amphioxus, represented (in part) by a ribbon of sections "some yards long".

The original instrument continued in almost daily use in Sedgwick's laboratory at Cambridge for many years after newer patterns had been invented, giving results equal to those of the best of them; and I think I am right in stating that it was still employed when I left Cambridge in 1908. Threlfall had added one essential improvement to Caldwell's original idea. This was the introduction of a method by which the sections were arranged on slides coated with a dilute solution of rubber, by which they became attached to the slide, so that the paraffin could be dissolved without disturbing any of the loose parts. Slides containing sections prepared by the method of Caldwell and Threlfall can be read like the consecutive pages of a book, instead of, as previously, like an incomplete series of detached pages frequently imperfect and out of order. Biological science has to acknowledge a deep debt of gratitude to Threlfall for designing the first automatic microtome.

Melbourn, Cambs,

SIDNEY F. HARMER. Sept. 7. 